\title{
JURISPRUDENCIA ITALIANA COMENTADA
}

\author{
Rodrigo Míguez Núñez \\ Profesor de Derecho Civil \\ Universidad Alberto Hurtado
}

Por una ReLeCtura DEL ESTATUTO DE LOS BIENES PÚBLICOS:

BIENES COMUNES EN LA CASACIÓN ITALIANA (Corte Suprema de Casación Sez. UN. 14 FEBRERO 2011, No 3665 )

La sentencia que motiva esta nota surge a raíz de una acción de constatación de dominio interpuesta ante el Tribunal de Venecia por una sociedad privada $^{1}$ respecto de uno de los varios valles de pesca existentes en la parte meridional de la laguna veneciana ${ }^{2}$. La administración estatal requerida ${ }^{3}$ rechazando la demanda, reconviene solicitando la declaración de la naturaleza demanial del bien. Las sentencias de primer y segundo grado ${ }^{4}$, negando la condición de propiedad privada del área, confirman la demanialidad sobre la base de argumentos historiográficos

${ }^{1}$ Azienda marina Averto S.R.L.

${ }^{2}$ Por valles de pesca se entienden las zonas de la laguna de Venecia, rodeados por terraplenes o cercas donde se practica la "vallicoltura", una especie de piscicultura extensiva.

${ }^{3}$ El Ministerio de Economía y de las Finanzas, el Ministerio de las Infraestructuras y de los Transportes, la Agencia del Demanio y la Región del Veneto.

${ }^{4}$ Tribunal de Venecia, sentencia 543, publicada el 3 de marzo de 2003; Corte de Apelaciones de Venecia, sentencia 818, de fecha 8 de abril de 2008 y publicada el 8 de mayo del mismo año. que corroboran la calidad de "propiedad pública” de la laguna por pertenecer al "demanio marítimo necesario de origen natural". En consecuencia, se ordena a la sociedad demandante la entrega de las áreas consideradas demaniales y el pago, a favor de la administración pública, de una suma a título de ocupación ilícita del sitio (cuyo monto se determinará en juicio separado). El ente agraviado interpone recurso de casación censurando las consideraciones de la Corte de Venecia invocando dos argumentos. Por una parte, porque la demanialidad del valle se ha declarado sin mediar disposición de la pública administración, por una mera clasificación legal y, por la otra, porque la presunta demanialidad debió reputarse cesada en virtud del constante desinterés del Estado que, además de no haber adoptado alguna medida de tutela, autorizó numerosos actos incompatibles con la pretendida naturaleza pública de la zona.

Conociendo del recurso, la Corte Suprema de Casación, reunida en Secciones Unidas, confirma la sentencia de segundo grado siguiendo un iter argumentativo parcialmente diverso al de la sentencia recurrida. La casación decide ampliar e integrar las consideraciones del fallo a la luz del pluralismo de fuentes del actual sistema 
de Derecho Civil reconociendo una noción de "bien público" aferrada en el requisito de la "funcionalidad" a la persecución de los intereses de la colectividad.

El razonamiento de la Corte se articula sobre la base de los siguientes elementos:

- la base legal de la reglamentación de los bienes públicos se encuentra en els art. 822 y ss. del $C C$;

- tal reglamentación no es exhaustiva ni suficiente

"resultando indispensable integrarla con varias fuentes del ordenamiento y específicamente con las normas constitucionales";
- así, y aun cuando no exista una definición constitucional de los bienes públicos, de los arts. 2, 9, 42 y 117 de la Constitución es posible colegir que el principio "personalista" ${ }^{5} \mathrm{se}$

\footnotetext{
${ }^{5} \mathrm{El}$ art. 2 de la Cons. Pol. italiana representa la principal norma del enunciado principio. Según ésta la república reconoce y garantiza los derechos inviolables del hombre (como individuo o en las formaciones sociales donde él desarrolla su personalidad) y exige el cumplimiento de los deberes inexcusables de solidaridad política, económica y social. El individuo, por tanto, es considerado el centro de la organización política y social y así titular de derechos anteriores al Estado. De lo anterior deriva la prioridad axiológica de la persona humana respecto al Estado y a la entera organización de los poderes públicos. El art. 9 de la Cons. Pol. tutela el paisaje y el patrimonio histórico y artístico de la nación. Dicha norma ha sido motor de una rica legislación en materia de bienes culturales, cuya relevancia se sintetiza en el Código de los Bienes Culturales contenido en el DL No 42 , del 22 de
}

debe también manifestar en el ámbito del "paisaje", entendido no sólo como demanio y patrimonio del Estado sino que, también, como un conjunto de aquellos

"bienes que, independientemente de una preventiva individualización por parte del le gislador, por su intrínseca naturaleza o finalidad resulten, sobre la base de una acabada interpretación del entero sistema normativo, funcionales al perseguimiento y a la satisfacción de los intereses de la colectividad";

- por lo tanto,

"de dicho cuadro normativoconstitucional, y establecido el dato "esencial" de la centralidad de la persona (y de sus relativos intereses), que se hace efectivo, además que con el reconocimiento de derechos inviolables, "mediante el cumplimiento de los deberes inderogables de la solidaridad política, económica y social", emerge la exigencia interpretativa de "mirar" el tema

enero del 2004. El art. 42 de la Cons. Pol., aun cuando prevalentemente referido a la propiedad privada, contiene el reconocimiento de la propiedad pública. Debe, además, apuntarse que una reforma constitucional realizada por la ley $\mathrm{N}^{\mathrm{O}} 3$ del 18 de octubre de 2001 ha modificado el título v de la parte segunda de la Constitución italiana, estableciendo la competencia exclusiva del Estado en materias de tutela del ambiente, del ecosistema y de los bienes culturales, entre otros temas relacionados (art. 117 Cons. Pol.). 
de los bienes públicos más allá de una visión estrictamente patrimonial-propietaria para alcanzar una perspectiva personal-colectivista";

- es por tal motivo que:

"discutir en términos de sola dicotomía bienes públicos (o demaniales) y privados significa, en modo parcial, limitarse a la mera individualización de la titularidad de los bienes, olvidando el ineludible dato de la clasificación de los mismos en virtud de la relativa función y de los relativos intereses a dichos bienes relacionados";

- de lo anterior deriva:

"allí donde un bien inmueble, independientemente de la titularidad, resulte por sus intrínsecas connotaciones, en modo particular por aquellas de tipo ambiental o paisajístico, destinado a la realización del Estado social como ya delineado, dicho bien ha de considerarse -fuera de la perspectiva del dominium romanista y de la propiedad codificada- 'común', es decir, prescindiendo del título de propiedad, instrumentalmente relacionado a la realización de los intereses de todos los ciudadanos".

Lo que en primer término merece ser enfatizado es que nada obsta para la afirmación de la naturaleza demanial del valle de pesca la carencia de un acto constitutivo de la administración pública. En casos como el que comentamos (donde el bien es considerado público por sus características físicas y ontológicas, esto es, objetivas) resulta absolutamente irrelevante la presencia de un acto administrativo que intervenga para declarar la demanialidad, pues, como lo ha afirmado en forma constante la doctrina

"la adquisición de la cualidad de bien público se relaciona a una situación dehechoyno aun acto jurídico" ${ }^{\prime}$.

En efecto, de acuerdo con el art. 27 letra b) del Código de la Navegación, forman parte del demanio marítimo, entre otros bienes, las lagunas (que se entienden comprensivas de los valles de pesca) y los embalses de agua salada que al menos durante una parte del año se comuniquen libremente con el mar. De esta forma, la laguna forma parte de los bienes del demanio de origen natural, de "propiedad pública necesaria" (o "reservada") por pertenecer al Estado o a otros entes públicos en razón de una elección general realizada por el legislador y no de una específica determinación administrativa ${ }^{7}$. Así las cosas, la calidad de bien público reservado de los valles de pesca no deriva de procedimiento

\footnotetext{
p. 2510.

${ }^{7}$ Cuestión que sí ocurre en Italia con los llamados "bienes demaniales a destinación pública" (como el demanio militar y las carreteras), donde dicha calidad se adquiere como consecuencia de la destinación del bien por parte de la administración a una función o servicio público.
}

${ }^{6}$ Para todas la voces, cfr. CASCIONE (2011), 
de la administración destinado a salvaguardar los intereses públicos, sino que de la misma ley que ha individuado, en forma general, los elementos tipológicos de la categoría ${ }^{8}$.

En segundo lugar interesa resaltar que la Corte examina, por la vía interpretativa, el sistema normativo vigente, con particular atención al ordenamiento constitucional, para individuar ciertos criterios destinados determinar la naturaleza "no privada" de un bien inmueble. En dicha tarea, el Tribunal Supremo introduce una noción constitucional de bien público inspirada en la funcionalidad a la satisfacción de los intereses de la colectividad. No puede omitirse, a este respecto, la evidente influencia de los textos civilistas sobre la lectura constitucional del derecho de propiedad $^{9}$ y de allí la posibilidad de aplicar de modo directo preceptos contenidos en la carta fundamental a fin de decidir el objeto de la causa ${ }^{10}$. Todavía, parece sorprender la directa

${ }^{8}$ Así, Lieto (2011), p. 355.

${ }^{9}$ Es obligatoria la cita de dos obras fundamentales sobre la cuestión: RoDOtà (1960), p. 1252 e ss., y la monografía de PerLingieri (1970). Para una reconstrucción de los aportes de la civilística italiana sobre la lectura constitucional del derecho de propiedad cfr. Carapezza Figlia (2011), pp. 1061-1088. Una revisión jurisprudencial de la creciente práctica de interpretación del Derecho Civil según la Constitución puede consultarse en PerLingIeri e Carapezza Figlia (2012), p. 11 y ss.

${ }^{10}$ De esta motivación se extrae la aplicación del concepto Drittwirkung der Grundrechte $o$, si se prefiere, de la eficacia horizontal de los derechos fundamentales. Para detalles e iniciales reenvíos véase RaIser (1990); Hesse (1995). Entre nosotros, reflexiones críticas sobre la aplicación directa de normas constitucionales en el Derecho Civil han sido desarrolladas por CoRRAL TALCIANI (2004), pp. 47-63. aplicabilidad de dichas disposiciones; lo interesante, a nuestro juicio, estriba en que la Corte ha interpretado la disciplina de los bienes según un criterio que considera demanial un bien mediante la atribución de un "significado constitucional" a su "uso". Dicho en otras palabras, lo que aquí se planeta es una interpretación constitucionalmente orientada de la teoría de los bienes y es por ello que la necesidad de superar el miramiento de los bienes públicos desde la rígida perspectiva del $C C$ resulta incuestionable al criterio de la Corte.

Con todo, es preciso notar que la tesis que determina la demanialidad de un bien en razón de la realización de intereses de relevancia constitucional no debe entenderse como el seguimiento del criterio que adscribe única y exclusivamente a los bienes públicos la característica de llevar a cabo un interés público. Como apunta un atento observador, tal visión resulta superada por la "doctrina de interés público" la cual ha esclarecido en modo definitivo que los bienes de propiedad privada pueden también cumplir "finalidades de público interés", a veces correspondientes a aquellos servidos por los bienes públicos y por el mismo motivo sujetos a un particular régimen jurídico de vinculación ${ }^{11}$. Se advertirá, por lo demás, que de la concepción propietaria inserta en el art. 42 de la Cons. Pol. y del primado de la persona humana que fluye del art. 2 del mismo cuerpo legal se recaba un sistema propietario basado en una función social estatuida al servicio de la persona, de

${ }^{11}$ Lo destaca críticamente CARAPEZZA FIGLIA (2012), pp. 543-544. 
lo cual se colige una noción de dominio fundada en la solidaridad y en la accesibilidad de parte de todos al uso de los bienes, cualquiera sea su calidad. Dicha condición, se ha afirmado, resulta intermedia entre "la propiedad como dominio y la propiedad popular o la no propiedad" 12 .

Sobre la base del marco teórico constitucional hasta ahora delineado, surge un tercer elemento que conviene destacar: para la reconstrucción del sistema de bienes públicos, no interesa tanto el régimen de pertenencia del bien (visión clásica de "titularidad" ligada a la propiedad codificada) como su idoneidad al goce y disfrute colectivo (visión "funcional" ligada a la doctrina de los bienes comunes). Lo anterior comporta una desafección de la concepción tradicional que relaciona la calidad pública de un bien a su titularidad pública (oponiéndola, con el mismo criterio, a los bienes privados), para fijar la atribución de dicha calidad atendiendo a la funcionalidad del bien a intereses de naturaleza colectiva ${ }^{13}$. De lo dicho emerge, como se ha sostenido a raíz del presente fallo, una crisis del sistema tradicional de bienes establecido por el $C C$, ya que se produce una escisión entre pertenencia (titularidad) y destinación del bien ${ }^{14}$.

En Italia la disociación entre "título dominical" y "función pública" ha sido afirmada por diversas reconstrucciones

12 Berti (1976-1977), p. 998. Véase también Pedrini.

${ }^{13}$ En el análisis de la propiedad pública en clave funcional son pioneros los estudios de: $\mathrm{PU}$ GLIATTI (1954), p. 122 e ss.; GianNini (1963), p. 1 e ss.; Caputi Jambrenghi (1979), p. 2.

${ }^{14}$ Así, Cascione (2011), p. 2511. doctrinales ${ }^{15}$ como por la misma evolución del Derecho Positivo ${ }^{16}$. A este respecto, vale la pena recordar que el $C C$ italiano prevé expresamente en su art. 825 la figura jurídica de los derechos demaniales sobre cosa ajena. Señala la norma que el régimen de los bienes públicos se extiende a los derechos reales que corresponden al Estado, a las provincias y a los municipios cuando dichos bienes consientan el perseguimiento de fines de interés público. En doctrina, se evocan al interior de esta clase las servidumbres públicas (como las servidumbres eléctricas, art. 1056 del $C C$ ), los derechos de uso público (como las calles vecinales) y los usos cívicos $^{17}$, entre otras figuras. Tales situaciones encarnan la común distinción entre de titularidad del derecho de propiedad y el uso público de cosa ajena al fin de consentir el goce colectivo de ciertos bienes por una comunidad de habitantes.

${ }^{15}$ Son varias las voces en MATTEI et al. (2007). Véanse, además, los aportes consignados en el Annuario Aipda 2003 (2004), que recoge las actas del Convegno dell'Associazione Italiana dei Professori di Diritto Amministrativo (Florencia, 2-3 octubre 2003) sobre el tema Titolarità pubblica e regolamentazione dei beni. Debe, asimismo, advertirse que entre nosotros Alejandro Vergara Blanco ha propuesto un similar miramiento en el cambio de eje del debate respecto a los bienes nacionales de uso público. Cfr. Vergara Blanco (1999), pp. 82-83.

${ }^{16}$ Sobre el cual se verá, a propósito de esta sentencia, CORTESE (2011), p. 1174.

${ }^{17}$ Se trata de un tipo de propiedad colectiva no reconocida por el $C C$ y que encuentra una específica reglamentación en la ley (y su reglamento) $\mathrm{N}^{\mathrm{o}} 1766$ de 1927 y más recientemente en la ley $\mathrm{N}^{\circ} 97$ de 2004. Dichos usos presentan la característica de su no pertenencia a título de propiedad individual a personas físicas o jurídicas, por concernir su uso y goce a una comunidad de habitantes. 
Pues bien, en consideración a lo dicho la Casación afirma:

"el sólo aspecto de la demanialidad no parece exhaustivo para individuar bienes que, por su intrínseca naturaleza, o son caracterizados por un goce colectivo o, independientemente del título de propiedad público o privado, resulten funcionales a los intereses de la misma colectividad".

Y así, el aspecto dominical

"cede el paso a la realización de intereses fundamentales indispensables para el correcto desenvolvimiento de la personalidad humana".

La calificación jurídica de los valles de pesca debe ser encuadrada en dicha óptica, pues en virtud de la investigación realizada por el juez de instancia y documentada por amplia motivación, dichos valles presentan "una funcionalidad y una finalidad pública-colectiva" 18 .

Debe observarse que hace bastante tiempo la doctrina italiana insiste en la posibilidad de reglar bienes que, si bien escapan a la taxonomía clásica del $C C$, necesitan protección ya en razón de los sujetos que deben administrarlos, ya en por el interés que despiertan para la autoridad pública por su uso y utilidad

${ }^{18}$ Sostiene LieTo (2011), p. 340, citando relevante doctrina, que símil fenómeno se presenta en relación a los bienes culturales, los cuales son considerados públicos en razón de su goce y no por su régimen de pertenencia. colectiva. De este presupuesto emerge un cuarto y último aspecto a comentar: para atender a dichas necesidades lo que propone el fallo es una reinterpretación de los bienes públicos a la luz de la doctrina de los bienes comunes. Así razonando, las Secciones Unidas de la CS utilizan por primera vez en la jurisprudencia italiana la categoría de los bienes comunes conectándose con la elaboración teórica ofrecida por doctrina de los últimos años.

Hemos ya esclarecido que para la Corte el tema de los bienes públicos no es un problema propietario; el Supremo Colegio ha querido premiar una lectura social del uso y de administración de las cosas prescindiendo del recurso a la propiedad y revindicando la importancia de la función pública que aquellas cosas desarrollan, independientemente de la atribución del derecho dominical $^{19}$. Y allí, en el tentativo de legitimar una concepción del bien ligada a su destino, se torna necesario recurrir a un discurso que permita tutelar aquellos bienes -llamados comunes- considerados funcionales a la satisfacción de derechos fundamentales moviéndose más allá de la estrecha dicotomía de la propiedad pública y privada ${ }^{20}$. De esta forma, del principio de la solidaridad que fluye del art. 2 de la Cons. Pol. emana la necesidad de garantizar

"todas las condiciones esenciales que consienten la efecti-

${ }^{19}$ Así, Cortese (2011), p. 1177.

${ }^{20}$ Comentando el presente fallo, remarca la convergencia entre el concepto de bienes comunes y tutela de valores de la persona humana Carapezza Figlia (2012), p. 540 y bibliografía allí citada. 
vidad de los derechos fundamentales para el desarrollo y evolución de la personalidad",

deber cuyo cumplimiento compete a los ciudadanos como a las instituciones $^{21}$.

Todavía, se notará que para proceder al reconocimiento de este planteamiento se requiere una reforma orgánica -como la recientemente propuesta en Italia por la Comisión sobre los Bienes Públicos ${ }^{22}$ - sobre la base de la cual se clasifiquen los bienes en forma funcional, o sea, en miras a la exigencias sustanciales a las que son llamados, por su idoneidad, a satisfacer. En este motivo justifica cierta doctrina la exigencia de diferenciar la categoría de los bienes comunes de los bienes públicos, agregándose al contraste la necesidad de afirmar, mediante el reconocimiento del estatuto de los primeros, el principio de la "indisponibilidad absoluta" de los bienes considerados esenciales para la existencia humana frente a los procesos de privatización ${ }^{23}$.

Los valles de pesca configuran un caso de combinación de los principios de desarrollo de la persona, tutela del paisaje y de la función social de la propiedad y por tal motivo dan origen a una concepción de bien público entendido como instrumento dirigido a la realización de valores constitucionales.

${ }^{21}$ Lieto (2011), p. 350

${ }^{22}$ Instituida por decreto del Ministerio de Justicia en junio de 2007 con la tarea de elaborar un proyecto de ley para la modificación de las normas del $C C$ en materia de bienes públicos. La Comisión, presidida por el civilista Stefano Rodotà, entregó el proyecto al Ministerio de Justicia en febrero de 2008.

${ }^{23}$ Así, Lieto (2011), pp. 348-349.
En efecto, debe destacarse que el desarrollo de la noción de función social de la propiedad unida a la promoción de la personalidad humana ha sido la llave para la elaboración, por vía interpretativa, de un estatuto de los bienes comunes compatible con la naturaleza privada o pública de la titularidad de los mismos ${ }^{24}$. Lo anterior permite una ulterior potencialidad de la normativa constitucional al descubrirse que la categoría de los bienes paisajísticos, como en la especie, no existe únicamente para ser protegida o conservada, sino que, además, como recurso que la comunidad entera debe gozar en cuanto funcional para su desarrollo ${ }^{25}$.

A la asociación entre satisfacción de derechos fundamentales y funcionalidad de intereses colectivos atienden los bienes comunes y en esta dirección doctrinaria la Corte de Casación propone una lección metodológica de una categoría aún en fase de elaboración y que, como tal, necesitará continuar su maduración conceptual para concretar el paso definitivo de la "titularidad" a la "destinación" 2627.

${ }^{24}$ Así, Carapezza Figlia (2012), pp. 540541. Agrega el autor, a modo de ejemplo, la disciplina de los recursos hídricos (DL $\mathrm{N}^{\circ}$ 152 del 3 de abril de 2006, art. 141 y ss.), del patrimonio natural (ley No 394 del 6 de diciembre de 1991) y de los bienes culturales y paisajísticos (DL No 42 del 22 de enero de 2004).

${ }^{25}$ LiETo (2011), p. 345.

${ }^{26}$ Sobre este pasaje, que caracteriza la reciente evolución de los bienes públicos, es didáctico Gambaro, (2007), p. 57.

${ }^{27} \mathrm{El}$ lector interesado en profundizaciones sobre el presente consultará también: PELLECCHIA (2012), p. 573 ess. y Vezzoso (2011), pp. 892-907. 
Bibliografía

Annuario Aipda 2003, (2004). Milano: Giuffrè.

Berti, Giorgio (1976-1977). "Recenti scritti di giuspubblicisti intorno alla proprietà". Quaderni Fiorentini. $\mathrm{N}^{\mathrm{O}}$ 5-6, Milano.

Caputi Jambrenghi, Vincenzo (1979). Premesse per una teoria dell'uso dei beni pubblici, Napoli, Jovene.

Carapezza Figlia, Gabriele (2012). "Proprietà e funzione sociale. La problematica dei beni comuni nella giurisprudenza delle Sezioni unite". Rassegna di Diritto Civile. $\mathrm{N}^{\circ} 2$, Napoli.

Carapezza Figlia, Gabriele (2011). "Premesse ricostruttive del concetto di beni comuni nella civilistica italiana degli anni Settanta". Rassegna di Diritto Civile. No 4, Napoli.

Cascione, Claudia Morgana. (2011). "Le Sezioni unite oltre il codice civile. Per un ripensamento della categoria dei beni pubblici. Giurisprudenza Italiana. $\mathrm{N}^{\circ} 12$, Torino.

Corral Talciani, Hernán (2004). "Constitucionalización del Derecho Civil: ¿hasta dónde y de qué modo?". Derecho Mayor, $\mathrm{N}^{\mathrm{o}} 3$, Santiago.

Cortese, Fulvio (2011). "Dalle valli da pesca ai beni comuni: la Cassazione rilegge lo statuto dei beni pubblici?". Giornale di Diritto Amministrativo. $\mathrm{N}^{\circ}$ 11, Milanofiori, Assago.

Gambaro, Antonio (2007). "Gli statuti dei beni pubblici", in Ugo Mattei Ugo et al. (2007). Invertire la rotta. Idee per una riforma della proprietà pubblica, Bologna, Il Mulino.

Giannini, Massimo Severo (1963). Ibeni pubblici, Roma, Bulzoni.
Hesse, Konrad (1995). Derecho constitucional y derecho privado. Traducción e introducción de Gutiérrez Gutiérrez. Madrid: Civitas.

LiEto, Sara (2011). "Beni comuni, diritti fondamentali e stato sociale. La Corte di Cassazione oltre la prospettiva della proprietà codicistica". Politica del Diritto. No 2, Bologna.

Mattei Ugo et al. (2007). Invertire la rotta. Idee per una riforma della proprietà pubblica, Bologna, Il Mulino.

Pedrini, Federico, "Note preliminari ad uno studio sui diritti costituzionali economici". www.forumcostituzionale.it. consultada el 6 de octubre de 2013.

Pellecchia, Enza (2012). "Valori costituzionali e nuova tassonomia dei beni: dal bene pubblico al bene comune". Foro Italiano. $\mathrm{N}^{\mathrm{o}} 2$, Bologna.

Perlingieri, Giovanni e Gabriele CarapeZza Figlia (2012). "Introduzione", in Giovanni Perlingieri e Gabriele CARAPEZZa Figlia (coords.). L'interpretazione secondo Costituzione' nella giurisprudenza. Crestomazia di decisioni giuridiche. Napoli: Edizioni Scientifiche Italiane, vol. I.

Perlingieri, Pietro (1970). Introduzione alla problematica della proprietà, Camerino-Napoli, Edizioni Scientifiche Italiane.

Pugliatti, Salvatore (1954). "Strumenti tecnico-giuridici per la tutela dell'interesse pubblico nelle proprietà" (1939). Salvatore Pugliatti. La proprietà nel nuovo diritto, Milano, Giuffrè.

Raiser, Ludwig (1990). Il compito del Diritto Privato. Trad. de Michele Graziadei. Milano: Giuffrè.

Rodotà, Salvatore (1960). "Note critiche in tema di proprietà". Rivista trimestrale di diritto e procedura civile. $\mathrm{N}^{\circ}$ XIV. Milano. 
Vergara Blanco, Alejandro (1999). "Na- Vezzoso, Giovanni (2011). "Criteri identuraleza jurídica de los 'bienes nacionales de uso público'”. Ius Publicum, $\mathrm{N}^{\mathrm{o}}$ 3, Santiago. tificativi della demanialità delle valli da pesca". Il Diritto Maritimo. No 3 , Genova.

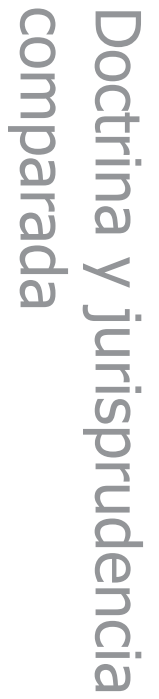

